\title{
The Phycomycete Catenaria anguillulae: Growth Requirements
}

\author{
By R. A. NOLAN* \\ Department of Botany, University of California, Berkeley, \\ California 94720 , U.S.A.
}

(Accepted for publication 20 October 1969)

SUMMARY

The physical factors and nitrogen requirements for the growth of the aquatic phycomycete Catenaria anguillulae in liquid shaken cultures from measured zoospore inocula were examined. Growth was determined by measuring mycelial dry weight and rate of titratable acid production. The optimum $\mathrm{pH}$ range for growth was $\mathrm{pH} 8 \cdot 2$ to $8 \cdot 7$. The toxicity of the $\mathrm{pH}$ indicators used was assessed. The optimum temperature for growth was $25^{\circ}$. The organism was highly aerobic. Inorganic nitrogen sources were not utilized. When organic nitrogen sources were supplied individually, L-aspartic acid, L-asparagine, L-glutamic acid, L-arginine, DL-citrulline and L-ornithine were utilized. Asparagine was the best single source. When the $\mathrm{N}$ sources were supplied as Difco vitamin-free Casamino acids, only lysine, methionine and arginine were utilized during the lag phase. During the more rapid phase of growth, all of the amino acids detected in the Casamino acids were utilized. When the vitamin-free Casamino acids were replaced by an equivalent amino acid mixture, the subsequent decrease in yield was not corrected by adding $\mathrm{NaCl}$, oleic acid or stearic acid. The optimum concentrations of various $\mathrm{N}$ sources were determined. The medium finally evolved contained L-asparagine + L-lysine as $\mathbf{N}$ sources.

\section{INTRODUCTION}

Catenaria anguillulae was classified as a member of the Order Chytridiales until Couch (I945) transferred it to the Order Blastocladiales. This change was made on the basis of similarities between the genus Catenaria and members of the Order Blastocladiales with respect to zoospore structure and behaviour, nature of hyphal septations, origin and germination of the resistant sporangium and life cycle. A review of nutritional studies of the aquatic Phycomycetes (Cantino \& Turian, I959) indicated that members of the Order Chytridiales could utilize inorganic nitrogen and sulphur sources and could either synthesize all vitamins or required thiamine for growth. Members of the Order Blastocladiales could neither utilize inorganic sulphur sources nor synthesize thiamine. Some isolates had additional vitamin requirements and, whereas most isolates could utilize inorganic nitrogen sources, one had lost this ability.

The first purpose of the present work was to examine the nutritional requirements of Catenaria anguillulae and to determine its nutritional relationship to members of the Orders Chytridiales and Blastocladiales. The second purpose was to analyse the nutritional behaviour of $C$. anguillulae to provide data for the interpretation of eco-

* Present address: Department of Biology, New Mexico State University, Las Cruces, New Mexico 880oI, U.S.A. 
logical information and for future studies on the enzymology of its amino acid metabolism. A brief abstract of earlier phases of this study has been published (Nolan, I966).

\section{METHODS}

Origin and maintenance of the isolate used. All of the present work was done with an isolate of Catenaria anguillulae Sorokin (strain 58-I2) obtained from Dr R. Emerson (Department of Botany, University of California, Berkeley, Calif., U.S.A.). The fungus had been isolated into axenic culture from material infecting nematodes (Hemicycliophora arenaria). The infected nematodes and their identification had been kindly supplied by Dr R. Mankau (Department of Plant Nematology, Citrus Experiment Station, Riverside, California). Stock cultures were maintained on slopes of a yeastextract + soluble-starch medium (EYPSS; Emerson, I94I) and were transferred at intervals of 2 to 4 weeks. These cultures were incubated at $17 \pm 1^{\circ}$.

Inoculum preparation. The method used to obtain a zoospore inoculum was a modification of the technique used by Carlile \& Machlis (1965) for obtaining male gametes of Allomyces species. The concentration of zoospores obtained was I to $5 \times 10^{6} / \mathrm{ml}$. One $\mathrm{ml}$. of this suspension or a dilution of it was used to inoculate each flask in an experiment. Zoospore concentrations were determined with a haemacytometer. The viability of the zoospores used in each experiment was tested by adding I ml. inoculum to a small Petri dish containing EYPSS agar medium and by examination for subsequent germination and growth.

Chemicals and stock solutions. L-aspartic acid (A grade) was obtained from Calbiochem (Los Angeles, California), all other amino acids were obtained from Nutritional Biochemicals Corp., (Cleveland, Ohio). The $\mathrm{pH}$ indicators were obtained from Matheson, Coleman \& Bell (Norwood, Ohio) The fatty acids were obtained from Nutritional Biochemicals Corp. The yeast extract and vitamin-free Casamino acids were obtained from Difco Laboratories (Detroit, Michigan). The micronutrients were of analytical grade where available.

All stock solutions were prepared with glass double-distilled water and stored at $4^{\circ}$ in glass-stoppered bottles.

Preparation of glassware and media. All glassware was chemically cleaned (concentrated $\mathrm{H}_{2} \mathrm{SO}_{4}$ saturated with potassium dichromate) after having been machine-washed. The glassware was then rinsed several times with double-distilled water.

The experimental media were generally prepared and autoclaved in three portions: (a) the carbon source, $(b)$ the calcium and magnesium salts, $(c)$ the remainder of the medium. In some experiments, the nitrogen source was also autoclaved separately. All autoclaving was done for $15 \mathrm{~min}$. and at $120^{\circ}$. The fatty acids were added in ether solution to each sterile experimental flask before adding the remainder of the separately sterilized medium. The combined volume of the components was $50 \mathrm{ml}$./ flask. The initial $\mathrm{pH}$ value of a medium was always adjusted after mixing the separately autoclaved components and just before inoculation.

Growth of experimental cultures. All cultures were grown in $125 \mathrm{ml}$. Bellco flasks with stainless steel caps (Bellco Glass, Inc., Vineland, New Jersey). The inoculated flasks were placed on a horizontal rotary shaker ( $120 \mathrm{rev} . / \mathrm{min}$.) in a room maintained at $20 \pm \mathrm{I}^{\circ}$ (for exceptions see below and text). These conditions provided vigorous mixing and aeration. 
Two experimental regimes were maintained in Case glass anaerobic jars (19.5 inches $(50 \mathrm{~cm}$.) high $\times 7.75$ inches $(20 \mathrm{~cm}$.) diameter; Case Laboratories, Inc., Chicago, Illinois). Anaerobic conditions were obtained by evacuating a jar to $6.5 \mathrm{~cm}$. and then filling with $5 \%(\mathrm{v} / \mathrm{v}) \mathrm{CO}_{2}+95 \%(\mathrm{v} / \mathrm{v})$ hydrogen mixture. A catalyst, palladium-coated alumina pellets in a wire gauze sachet (Heller, 1954), and a reduced methylene-blue indicator (Baltimore Biological Laboratory, Cockeysville, Maryland; see Brewer, Allgeier \& McLaughlin, I966) were included in the jar. The $0.2 \%(\mathrm{v} / \mathrm{v})$ oxygen concentration was obtained by evacuating a jar twice to $7.5 \mathrm{~cm}$. $\mathrm{Hg}$ and filling each time with 'tank nitrogen'. The jars were placed on a low-speed horizontal, rotary shaker (6o rev./min.).

Adjustment of $p H$ value. The $\mathrm{pH}$ value of a culture was maintained by the addition of sterile $0.5 \mathrm{~N}-\mathrm{KOH}$ from a calibrated syringe. The amount of titratable acid produced in each culture flask was recorded as the amount of base required to return the culture medium to the original $\mathrm{pH}$ value; the $\mathrm{pH}$ value of the cultures was adjusted every 8 to $24 \mathrm{hr}$.

Yields of organism: dry weight. Cultures were harvested by vacuum filtration through previously tared filter papers. The papers were then placed in an oven $\left(90^{\circ}\right)$ for $24 \mathrm{hr}$, allowed to come to room temperature in a desiccator and weighed on a Mettler balance (Type H I6, Mettler Instrument Corp., Princeton, New Jersey). All dry weights are given to the nearest $\mathrm{mg}$. A constant dry weight (variation of less than I $\mathrm{mg}$. for repeated weighings) was obtained for any single culture flask harvested.

Acid production and dry weight served as criteria for comparing the growth of the fungus under the different experimental conditions. By comparing the growth curve and the rate of acid production (Fig. 5, 6) in an experiment, two types of information were obtained by following acid production: (I) the initial observation of acid production indicated the end of the lag phase of growth; (2) the slight inflexion in the acidproduction curve indicated when the peak of the growth curve had been reached.

The variation in dry weights between flasks in a single treatment was dependent upon the phosphate concentration in the medium. When the concentration of phosphate was $15 \mathrm{mM}$, the variation was $\pm 20 \%$ or less; when the phosphate concentration was Io $\mathrm{mM}$, the variation was $\pm 10 \%$ or less; at I mM phosphate the variation between the dry weights in a treatment was less than I mg.

Amino acid analyses. Culture filtrates were analysed for amino acid content according to the column chromatography technique of Moore \& Stein (1963). All determinations were made on a Beckman-Spinco automatic amino acid analyser (Model I20 B; Spinco Division, Beckman Instruments, Inc., Palo Alto, California) adjusted to a sensitivity such that $0.05 \mu \mathrm{M}$ of an amino acid could give a full scale deflexion. The filtrates were frozen at the time of harvest and then thawed and diluted with buffer before being added to the column. All amino acid concentrations were determined from the chromatograms by using the 'height-width' method of integration (see manual for analyser). The accuracy of the column data was $\pm 8 \%$. The data for ammonium concentrations are not given because of sensitivity to external conditions.

Standard micronutrients. Many of the media used contained a group of micronutrients which were always added at a fixed concentration; these are referred to as standard micronutrients (Table I). The concentrations of these ions were taken from Medium B (Machlis, 1953). 


\section{RESULTS}

Initial experiments. Early attempts to grow Catenaria anguillulae at $\mathrm{pH} 7 \cdot 0$ on a defined medium containing ammonium-N (Medium B in Table 2) were unsuccessful even with incubation for 54 days. Subsequently Medium B was modified by decreasing the total phosphate to I mM and by changing the $\mathrm{N}$ source to $\left(\mathrm{NH}_{4}\right)_{2} \mathrm{SO}_{4}$. The possibility of ammonium-N utilization (at I, IO, $30 \mathrm{~mm}-\mathrm{N}$ ) was then tested with this modified Medium $\mathrm{B}$ at $\mathrm{pH} 6 \cdot 2,7 \cdot 2$ and 8·2. After 25 days of incubation no growth had occurred.

Table I. Standard micronutrients of medium B (Machlis, 1953)

\begin{tabular}{|c|c|c|}
\hline & & $(\mathrm{mM})$ \\
\hline $\mathrm{Mn}$ & As $\mathrm{MnCl}_{2} \cdot 4 \mathrm{H}_{2} \mathrm{O}$ & 0.009 \\
\hline $\mathrm{Ca}$ & As $\mathrm{CoCl}_{2} \cdot 6 \mathrm{H}_{2} \mathrm{O}$ & 0.003 \\
\hline $\mathrm{Zn}$. & As $\mathrm{ZnSO}_{4} \cdot 7 \mathrm{H}_{2} \mathrm{O}$ & $0.00 \mathrm{I}$ \\
\hline $\mathrm{Cul}$ & As $\mathrm{CuSO}_{4} \cdot 5 \mathrm{H}_{2} \mathrm{O}$ & 0.001 \\
\hline $\mathrm{Fe}$ & As $\mathrm{FeCl}_{3} \cdot 6 \mathrm{H}_{2} \mathrm{O}$ & 0.018 \\
\hline B & As $\mathrm{H}_{3} \mathrm{BO}_{3}$ & 0.046 \\
\hline Mo & As $\mathrm{Na}_{2} \mathrm{MoO}_{4} \cdot 2 \mathrm{H}_{2} \mathrm{O}$ & 0.002 \\
\hline
\end{tabular}

Table 2. The composition of experimental media

The ratio of phosphates was adjusted to correspond to the initial $\mathrm{pH}$ value desired. All media contain the standard micronutrients (see Table I), D-glucose (I66 mM), $\mathrm{CaCl}_{2} \cdot 2 \mathrm{H}_{2} \mathrm{O}$ (0.5 mM), $\mathrm{MgCl}_{2} .6 \mathrm{H}_{2} \mathrm{O}(0.5 \mathrm{~mm})$ and thiamine. $\mathrm{HCl}$ ( $150 \mu \mathrm{g}$.).

\section{Components}

Nitrogen source (g. N/1.)

Difco Casamino acids

$\left(\mathrm{NH}_{4}\right)_{2} \mathrm{HPO}_{4}$

L-Asparagine

L-Lysine

Sulphur source (mM-S)

DL-Methionine

L-Methionine

Phosphate source (mM-P)

$\mathrm{K}_{2} \mathrm{HPO}_{4}$

$\mathrm{K}_{2} \mathrm{HPO}_{4}+\mathrm{KH}_{2} \mathrm{PO}_{4}$

$\mathrm{K}_{2} \mathrm{HPO}_{4}+\mathrm{KH}_{2} \mathrm{PO}_{4}+$ $\left(\mathrm{NH}_{4}\right)_{2} \mathrm{HPO}_{4}$

$\mathrm{pH}$ indicator (mg./1.) Bromocresol purple $m$-Cresol purple Other (see text)

$\mathrm{Na}_{2}$ EDTA (mM)

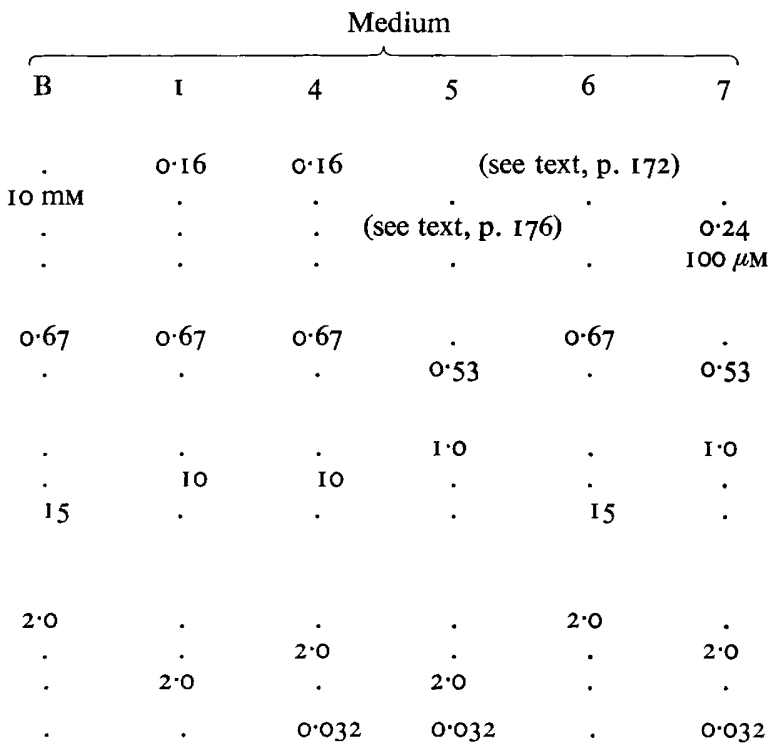

Growth occurred on Medium B only when the medium was supplemented with an organic nitrogen source. When L-glutamic acid was added to Medium B at 0.5 to Io mM, growth was noted after 20 days. The isolate was also able to grow on a glucose + yeast-extract + salts medium (GY 5) (Emerson, I958). A comparison of yeastextract and vitamin-free Casamino acids (each at $\mathrm{r}$ g./1.) as $\mathrm{N}$ sources in Medium $\mathrm{B}$ indicated that yields were higher with Casamino acids. 
$p H$ indicators. The indicators selected (Table 3 ) were added to Medium B + Casamino acids (I g./1.). The mean dry weights obtained in the different treatments were compared by using Duncan's multiple-range test ( $5 \%$ level, error degrees of freedom $=33$; see Steel \& Torrie, 1960). The means were in three distinct groups: indicators in group A (Table 3) were considered to be non-toxic; those in group B were slightly toxic; those in group $\mathrm{C}$ were highly toxic. There was no structural correlation among the members of any group; the chemical compounds present in the $\mathrm{pH}$ indicators used are far from being standardized and the possibility exists that phenolic intermediates might have been present in the products used (personal communication from Mr F. Green, Technical Director, Matheson, Coleman \& Bell). To avoid the introduction of additional variables, the stock solutions of the non-toxic indicators which were prepared for this experiment were used throughout the subsequent work. A later experiment indicated that xylenol blue and alizarine yellow $\mathrm{R}$ were also non-toxic.

\section{Table 3. The effect of various $p H$ indicators on the growth of Catenaria anguillulae}

The medium used was Medium B + Casamino acids ( $1 \cdot 0 \mathrm{~g} . / 1$.). Initial $\mathrm{pH} 7 \cdot 0$ maintained during the 7-day incubation period. The dry weights are the averages of 4 replicates.

$\begin{array}{lc}\text { Indicator (2.0 mg./l.) } & \begin{array}{c}\text { Dry weight } \\ \text { (mg.) }\end{array} \\ \text { Group A } & \\ \text { Bromocresol purple } & 27 \\ \text { m-Cresol purple } & 23 \\ \text { Cresol red } & 23 \\ \text { Control (no added indicator) } & 22 \\ \text { Phenol red } & 2 \text { I } \\ \text { Bromothymol blue } & 2 \text { I } \\ \text { Group B } & \\ \text { Thymol blue } & \text { I6 } \\ \text { Bromophenol blue } & \text { I4 } \\ \text { Group C } & \\ \text { Methyl red } & 5 \\ \text { Bromocresol green } & 5 \\ \text { Chlorophenol red } & 3 \\ \end{array}$

Optimal pH range. Butler \& Humphries (1932) studied the development of Catenaria anguillulae as it grew out from infected fluke eggs into various surrounding complex natural media. which varied from $\mathrm{pH} 6.5$ to 6.9 . These authors did not study the effects of $\mathrm{pH}$ value. I studied the effects of $\mathrm{pH}$ value on the growth of $C$. anguillulae in Medium I (Table 2). The results (Fig. 1 ) indicated that the optimum range for growth was $\mathrm{pH} 8 \cdot 2$ to $8 \cdot 7$.

Optimum temperature. The optimum temperature for the growth of Catenaria anguillulae strain 58-12 was determined using Medium I in static cultures. The results (Fig. 2) indicated that $25^{\circ}$ was the optimum temperature under these conditions; above $25^{\circ}$ and below $19^{\circ}$ the growth rate decreased rapidly.

Oxygen relations. Buckley \& Clapham (1929) investigated the viability of sporangia of Catenaria under a variety of conditions. From their experiments with the transfer of the growth of the fungus from infected fluke ova to previously uninfected ova in the presence of sewage with a high biological oxygen demand and in the presence of charcoaltreated water in paraffin-sealed tubes, they concluded that Catenaria could complete 
its development under anaerobic or nearly anaerobic conditions. To study the effects of degree of aeration on the amount of growth Catenaria anguillulae was grown in shaken cultures and in static cultures, in Medium I. An average dry weight of I $2 \mathrm{mg}$./ flask was produced in the shaken cultures, in contrast to an average dry weight of $28 \mathrm{mg}$./flask in the static cultures, after 9 days of incubation. This would seem to indicate $C$. anguillulae strain $58-12$ is an aerobic organism.

\section{Table 4. Composition of the vitamin mixture}

Personal communication from Dr S. Hutner, Haskins Laboratories, New York, to Dr L. Machlis; 25 September 1965 . The mixture is a dry mix, $50 \%$ of which is pentaerythritol. The concentrations listed below were obtained by adding $10 \mathrm{ml}$. of a stock solution to $\mathrm{I} 1$. medium.

\begin{tabular}{|c|c|c|c|}
\hline Vitamin & $\begin{array}{l}\text { Concen- } \\
\text { tration } \\
(\mu \mathrm{g} . / 1 .)\end{array}$ & Vitamin & $\begin{array}{l}\text { Concen- } \\
\text { tration } \\
(\mu \mathrm{g} . / 1 .)\end{array}$ \\
\hline Thiamine. $\mathrm{NO}_{3}$ & 180 & Putrescine. $2 \mathrm{HCl}$ & 60 \\
\hline Nicotinic acid & 240 & Spermidine phosphate. $3 \mathrm{H}_{2} \mathrm{O}$ & 30 \\
\hline Ca pantothenate & 300 & Folic acid & 12 \\
\hline $\mathrm{Na}$ riboflavin phosphate & 60 & DL-Carnitine. $\mathrm{HCl}$ & 120 \\
\hline Riboflavin & 30 & Betaine. $\mathrm{HCl}$ & 4800 \\
\hline Pyridoxamine. $2 \mathrm{HCl}$ & 60 & Choline $\mathrm{N}_{2}$ citrate & 4800 \\
\hline Pyridoxal. $\mathrm{HCl}$ & 60 & Cystamine $2 \mathrm{HCl}$ & 30 \\
\hline Inositol & 3000 & $\mathrm{~B}_{12}$ & $1 \cdot 2$ \\
\hline$p$-Aminobenzoic acid & 30 & Biotin & 3 \\
\hline
\end{tabular}

In another experiment two atmospheric regimes were produced to determine: (I) whether strain $58-12$ could grow under more strict anaerobic conditions; (2) whether strain $58-12$ could grow in the presence of $0.2 \%(\mathrm{v} / \mathrm{v})$ oxygen. Medium I without the usual thiamine source but supplemented with the vitamin mixture listed in Table 4 was used. The flasks were incubated at $23^{\circ}$ for 13 days for the anaerobic treatment and 7 days for the $0.2 \%(\mathrm{v} / \mathrm{v})$ oxygen treatment. Five replicates were used in each treatment. After 13 days of incubation the anaerobic flasks showed no visible growth and microscopic examination of their contents indicated no trace of the inoculum. After 7 days of incubation the flasks under the $0.2 \%(\mathrm{v} / \mathrm{v})$ oxygen treatment yielded an average dry weight of $2.0 \mathrm{mg}$./flask; microscopic examination of the contents of the flasks indicated that the fungus was growing, but very poorly. The $0 \cdot 2 \%(\mathrm{v} / \mathrm{v})$ oxygen treatment, because of the way it was obtained, also contained $3 \times 10^{-4} \% \mathrm{CO}_{2}$. It is clear that Catenaria anguillulae is neither anaerobic nor microaerophilic.

The optimum concentration of vitamin-free Casamino acids. The optimum concentration of vitamin-free Casamino acids was determined in Medium 6 (Table 2) but without ammonium phosphate. The results (Fig. 3) indicate that the optimum concentration of Casamino acids in this medium was about $2 \cdot 0 \mathrm{~g}$. $/ 1$., equivalent to $0 \cdot 16 \mathrm{~g} . \mathrm{N} / \mathrm{l}$. Medium without added glucose was included to test availability of the Casamino acids at I g./l. as carbon sources. After 7 days of incubation only $4 \mathrm{mg}$. dry weight was produced.

Growth on an artificial Casamino acids mixture. An attempt was made to replace the casein hydrolysate (Casamino acids) with a mixture containing the same amino acids and in the same proportions (Table 5). The concentration of methionine used in the mixture was a departure from its concentration in the hydrolysate, in order to maintain the concentration at which methionine had normally been included in other 
media. Medium 4 (Table 2) was used in this experiment but with the new $\mathrm{N}$ sources. The $\mathrm{N}$ concentrations in the various media were adjusted to correspond to o (control), $0 \cdot 5, \mathrm{I}, 2,3$ and 4 times the total $\mathrm{N}$ concentration provided by the Difco product at the optimal concentration of $2.0 \mathrm{~g}$. $/ 1$. (Fig. 4). The decrease in yield can be seen by comparing the dry weight of $35 \mathrm{mg}$./flask obtained after 9 days of incubation on the artificial mixture with the dry weight of about $120 \mathrm{mg}$./flask obtained after the same period of time with the Difco hydrolysate (Fig. 5).

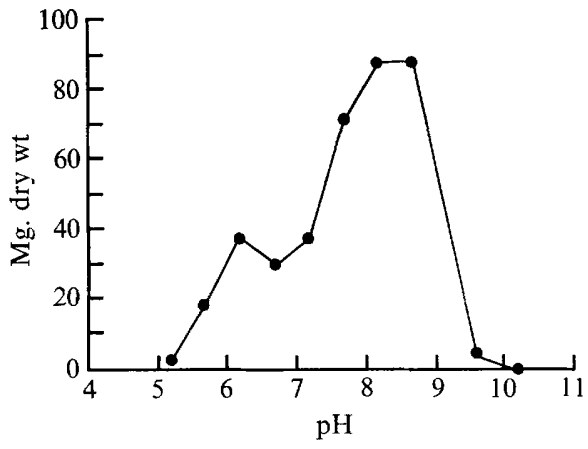

Fig. I

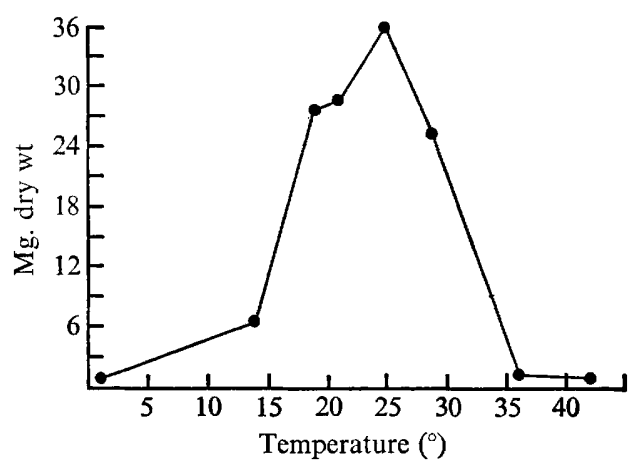

Fig. 2

Fig. I. The effects of $\mathrm{pH}$ on the growth of Catenaria anguillulae in Medium $\mathbf{I}$. The incubation period of the experiment was 7 days. Each point on the growth response curve represents the average of five to six replicates.

Fig. 2. The effects of temperature on the growth of Catenaria anguillulae in Medium I adjusted to a pH of 8.7. The $\mathrm{pH}$ indicator was $m$-cresol purple. The incubation period of the experiment was 9 days. Each point on the growth response curve represents the average of five replicates.

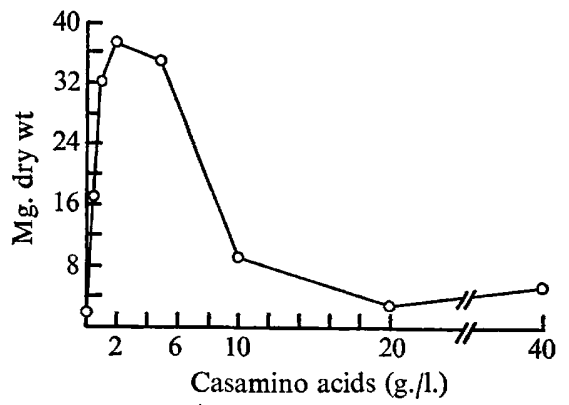

Fig. 3. The relation between growth of Catenaria anguillulae and the concentration of Difco Casamino acids in Medium 6 without the ammonium phosphate. The total phosphate was I $5 \mathrm{~mm}$; pH 6.9. Each point on the curve is the average of four replicate flasks. The incubation period 7 days.

Growth as measured by titratable acid produced is shown in Fig. 6. In an attempt to determine what critical factor(s) had been omitted from the medium in the change to a defined amino acid mixture two approaches were tried. 


\section{Effects of various ' Casamino factors'}

$\mathrm{NaCl}$. The Difco product is an acid $(\mathrm{HCl})$ hydrolysate of casein; and since the final $\mathrm{pH}$ value of the hydrolysate is adjusted with $\mathrm{NaOH}$, the final product contains $38 \%$ $\mathrm{NaCl}$ (Difco Manual, r953). Various concentrations of $\mathrm{NaCl}$ were added to Medium 4 adjusted to $\mathrm{pH} \mathrm{8.7.} \mathrm{In} \mathrm{this} \mathrm{experiment} \mathrm{the} \mathrm{artificial} \mathrm{amino} \mathrm{acid} \mathrm{mixture} \mathrm{was} \mathrm{the} \mathrm{N}$ source. Low concentrations of $\mathrm{NaCl}(0.00325,0.0065,0.013 \mathrm{M})$ were stimulatory to the

\section{Table 5. The composition of Difco vitamin-free Casamino acids (Column A) and of the amino acid mixture (Column B)}

\begin{tabular}{|c|c|c|}
\hline Amino acid & $A(\%)$ & B (g. N/l.) \\
\hline Arginine & 2 & $0.0064(L)$ \\
\hline Aspartic acid & 5 & $0.0160(\mathrm{~L})$ \\
\hline Glutamic acid & I 5 & $0.0480(\mathrm{~L})$ \\
\hline Glycine & I & 0.0032 \\
\hline Histidine & I. 5 & $0.0048(\mathrm{DL})$ \\
\hline Isoleucine & 4 & $0.0128(\mathrm{DL})$ \\
\hline Leucine & 5 & $0.0160(\mathrm{~L})$ \\
\hline Lysine & 5 & $0.0160(\mathrm{DL})$ \\
\hline Methionine & I & $0.0080(\mathrm{DL})$ \\
\hline Phenylalanine & 2 & $0.0064(\mathrm{DL})$ \\
\hline Threonine & 2 & 0.0064 (DL) \\
\hline Tyrosine & $\mathbf{I}$ & $0.0032(L)$ \\
\hline Valine & 4 & $0.0128(\mathrm{~L})$ \\
\hline Total & $48 \cdot 5$ & 0.1600 \\
\hline
\end{tabular}

growth of strain 58-1.2 on this medium but did not account for the differences between the two nitrogen sources (Fig. 7).

Fatty acids. Arai \& Kuwahara (196I) found that Streptococcus hemolyticus (s-8 strain) grew well on Difco vitamin-free Casamino acids but poorly on the etherextracted Casamino acids; they concluded that the ether treatment removed a factor important for the growth of this streptococcal strain. The factor remained active in the ether extract and was found to be stearic acid which was present in the Casamino acids at 0.001 to $0.01 \%$. Only saturated fatty acids (palmitic, arachidic) were able to replace the stearic acid. Demain, Hendlin \& Newkirk (1959) with a Sarcina species found that on a defined amino acid medium the final yield was increased to one-half of the maximum yield obtained on a celsein hydrolysate medium when they added; oleic acid $0.13 \mu \mathrm{g} . / \mathrm{ml}$., linoleic acid, $0.16 \mu \mathrm{g}$. $/ \mathrm{ml}$., linolenic acid $0.32 \mu \mathrm{g}$. $/ \mathrm{ml}$. or Tween $805.5 \mu \mathrm{g}$. $/ \mathrm{ml}$. Thus unsaturated and saturated fatty acids were active in replacing, or actually may be, the active factor(s) lost in changing from a medium containing casein hydrolysate to one with a defined amino acid mixture as the nitrogen source.

For the experiment with Catenaria anguillulae oleic acid was selected as the unsaturated fatty acid and stearic acid as the saturated fatty acid. Medium 4 with the amino acid mixture ( $0.16 \mathrm{~g}$. $\mathrm{N} / 1$.) as the $\mathrm{N}$ source was used. All three concentrations of oleic acid which were tested and stearic acid at $0 \cdot \mathrm{I}$ and $\mathrm{I} \cdot \mathrm{O} \mu \mathrm{g} \cdot / \mathrm{ml}$. were stimulatory to C. anguillulae strain 58-12 in the medium containing the artificial amino acid mixture 
(Fig. 8). The twofold increase in final dry weights was not, however, sufficient to account for the nearly fourfold difference between these results and those on the medium containing the Difco Casamino acids.

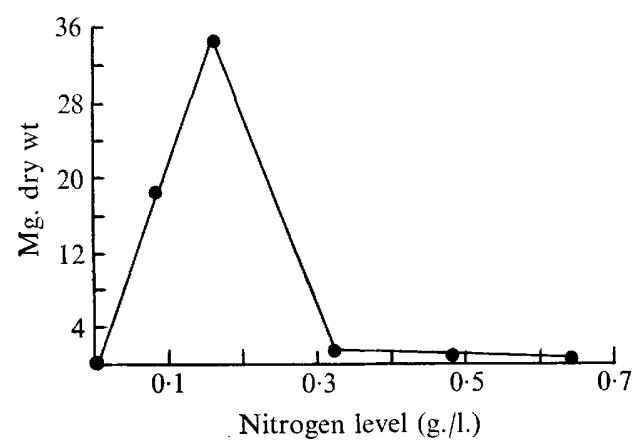

Fig. 4

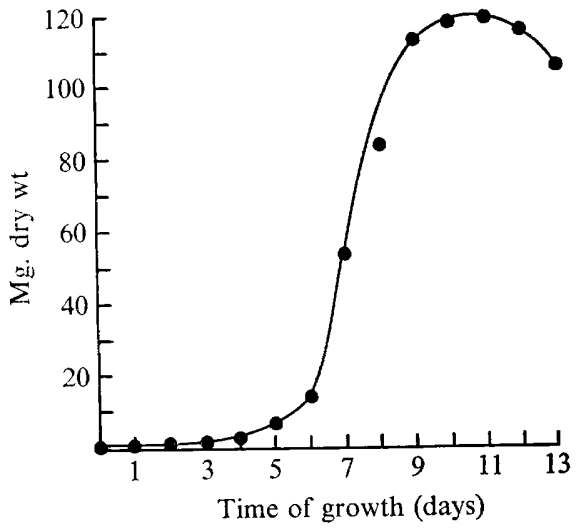

Fig. 5

Fig. 4. The relation between growth of Catenaria anguillulae and the concentration of the artificial amino acid mixture in Medium 4 . The incubation period was 9 days, $\mathrm{pH} 8 \cdot 7$. Each point on the curve is the average of six replicates.

Fig. 5. The growth curve of Catenaria anguillulae on Medium 4. Each point on the curve is the average of three to four replicates.

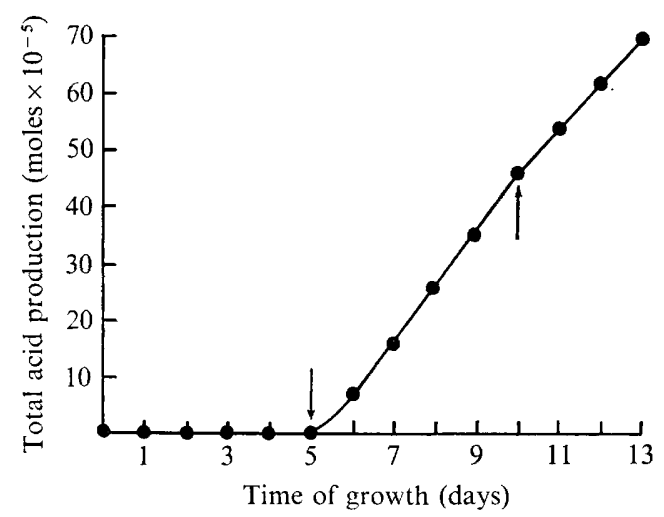

Fig. 6. Total titratable acid produced by Catenaria anguillulae when grown on Medium 4. Each point on the curve represents data from $10 \mathrm{pH}$ adjustments or observations. The arrows indicate end of lag phase and peak of growth curve.

Utilization of single amino acids. The results (Table 6) indicated that the compounds in the ornithine + urea cycle, including glutamic acid, were utilized along with asparagine and aspartic acid. Because of the way in which the medium was prepared, the concentration of L-aspartic acid in the final medium was equivalent to $0.065 \mathrm{~g}$. N/l., or one-half of the $\mathrm{N}$ concentration provided by the other compounds tested. Of the single $\mathrm{N}$ sources tested, L-asparagine gave the highest yield of organism for the I I-day incubation period; and this yield compared well with the yield obtained on the Difco Casamino acids at the same $\mathrm{N}$ concentration. $\mathrm{L}$-asparagine was therefore used in further experiments. 
The optimum concentration of $L$-asparagine. The amide $L$-asparagine was incorporated into Medium 5 at concentrations from o (control) to $0.48 \mathrm{~g}$. N/l. The medium was initially adjusted to $\mathrm{pH} 8 \cdot 7$. The results (Fig. 9) indicated that the optimum concentration

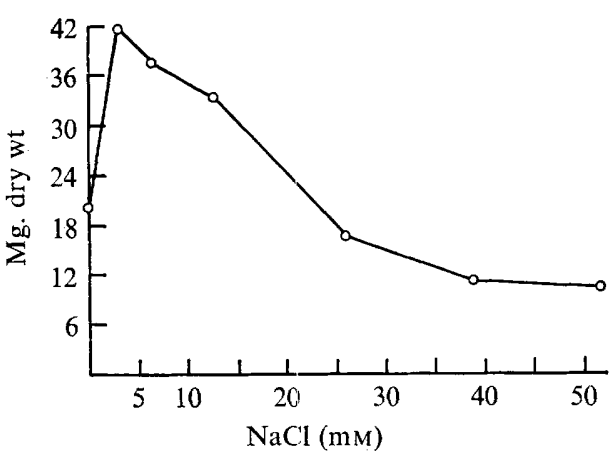

Fig. 7

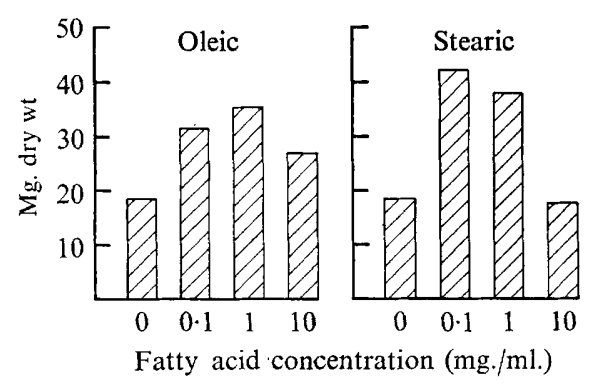

Fig. 8

Fig. 7. The relation between growth of Catenaria anguillulae and concentration of $\mathrm{NaCl}$ in Medium 4 with the amino acid mixture as the nitrogen source $(0 \cdot \mathrm{I} 6 \mathrm{~g}$. N/1.). The incubation period 12 days; results of each treatment are the average of five replicates.

Fig. 8. The relation between the growth of Catenaria anguillulae and the concentration of oleic acid and stearic acid in Medium 4 with the amino acid mixture as the nitrogen source $(0.16 \mathrm{~g}$. N/1.). Incubation for 9 days; results of each treatment average of three replicates.

\section{Table 6. The growth of Catenaria anguillulae on organic nitrogen sources in Medium 5 at $\mathrm{pH} 8.7$}

The incubation period I I days; the dry weights averages of duplicate flasks. The $\mathrm{N}$ concentration was $0.13 \mathrm{~g}$. N/l. except for L-aspartic acid $(0.065 \mathrm{~g}$. N/1.). For DL-mixtures the concentration is given for the $\mathrm{L}$-isomer only.

Yield
dry
weight
(mg.)

Control (no added nitrogen)

Difco Casamino acids

DL-Alanine

L-Arginine

L-Asparagine

L-Aspartic acid

DL-Citrulline

L-Cystine

L-Glutamic acid

L-Ornithine
Yield

dry weight

Nitrogen source (mg.)

of L-asparagine for the growth of Catenaria anguillulae on this medium was $0 \cdot 24 \mathrm{~g} . \mathrm{N} / 1$. The inoculum used was small in this experiment and accounted for the lower yield in comparison with the I I-day dry weight obtained with asparagine in the single $\mathrm{N}$ source survey.

The use of amino acids from a mixture. In studying the use of amino acids by an organism, an alternative to the method of supplying single sources is to provide the organism with a mixture of amino acids and then record the effects of the removal of 
amino acids from this medium. One problem which arises in such studies is the possibility that the organism may remove an amino acid from a mixture even though it will not grow on that amino acid when it is supplied as sole $\mathrm{N}$ source. Inhibitory interactions between amino acids in a mixture also present a problem. Prescott, Peters \& Snell (1953) found that alanine inhibited the growth of Lactobacillus delbrueckii and that this inhibition was annulled by serine or some of its peptides. The role of peptides in the present work was not assessed; peptides do occur in Difco Casamino acids. The early amino acid analyses were allowed to run for $24 \mathrm{hr}$, long enough for peptides to be indicated in the column chromatography; their total $\mathrm{N}$ concentration was not calculated and no attempt was made to identify specific peptides.

Table 7. Amino acid concentrations in Medium 4 with Difco vitamin-free Casamino acids (2 g./l.) as the $N$ source after growth of Catenaria anguillulae

The analyses were made with a Beckman-Spinco automatic amino acid analyser; concentrations in $\mu \mathrm{M} / \mathrm{ml}$.

\begin{tabular}{|c|c|c|c|c|}
\hline & \multicolumn{4}{|c|}{ Time of incubation (days) } \\
\hline & o & 5 & 6 & 8 \\
\hline \multicolumn{5}{|c|}{ Amino acid concentration in culture } \\
\hline Lysine & $0 \cdot 744$ & 0.500 & $0.45 \mathrm{I}$ & 0.085 \\
\hline Histidine & 0.152 & 0.158 & 0.143 & 0.080 \\
\hline Arginine & 0.118 & 0.118 & 0.056 & Trace \\
\hline Aspartic acid & 0.657 & 0.630 & 0.638 & 0.277 \\
\hline Threonine & 0.363 & 0.406 & 0.363 & 0.083 \\
\hline Serine & $0.48 \mathrm{I}$ & 0.484 & 0.506 & 0.133 \\
\hline Glutamic acid & $\mathrm{I} \cdot 49 \mathrm{I}$ & $1 \cdot 372$ & $\mathrm{I} \cdot 430$ & 0.542 \\
\hline Proline & $\mathrm{I} \cdot 094$ & $1 \cdot 216$ & $1 \cdot 078$ & 0.640 \\
\hline Glycine & 0.257 & 0.238 & 0.264 & $0 \cdot 101$ \\
\hline Alanine & 0.363 & 0.392 & 0.407 & 0.160 \\
\hline Valine & 0.456 & 0.518 & 0.517 & 0.083 \\
\hline Methionine & 0.753 & 0.644 & 0.418 & 0.139 \\
\hline Isoleucine & 0.344 & 0.378 & 0.352 & 0.027 \\
\hline Leucine & 0.620 & 0.644 & 0.649 & $0.05 \mathrm{I}$ \\
\hline Tyrosine & Trace & Trace & Trace & Trace \\
\hline Phenylalanine & 0.109 & 0.098 & 0.094 & Trace \\
\hline
\end{tabular}

The disappearance of an amino acid from a mixture may not always mean that it has been taken up by the organism. Kihara, Klatt \& Snell (1952) and Peters, Prescott \& Snell (1953) reported for different bacteria the presence of an extracellular tyrosine decarboxylase which partially destroyed the free amino acid in the media before any utilization. Gale (I945) reported an instance in which a Streptococcus species converted free arginine to ornithine, but that the latter compound was not utilized for growth. Even when an amino acid is taken up by the organism it does not mean that it will be utilized for growth. Halvorson \& Cowie (I96I) reported the uptake of various isomers and analogues of amino acids which were not utilized by a yeast.

For the present study, Catenaria anguillulae was grown in Medium 4 with Difco Casamino acids $(2.0 \mathrm{~g}$. $/ 1$.) as the $\mathrm{N}$ source. The growth curve (Fig. 5) and the curve for the production of titratable acid (Fig. 6) are from the present experiment. Through the lag phase of growth (5- and 6-day harvests; Table 7) the only amino acids removed from the medium in significant amounts (exceeding $\pm 8 \%$ of the concentration 
given in the o-day column of Table 7) were lysine, arginine and methionine. Methionine was the only sulphur source of those detected in the analysis and was known to be an excellent sulphur source for C. anguillulae (Nolan, 1966). From the studies on utilization of single amino acids, methionine was not shown to be a readily utilized $\mathrm{N}$ source. Arginine was readily utilized as a $\mathrm{N}$ source; but was not the only one of those compounds in the medium available to strain 58-I2. Of the compounds detected in the analysis, arginine, aspartic acid and glutamic acid were the ones utilized when given as

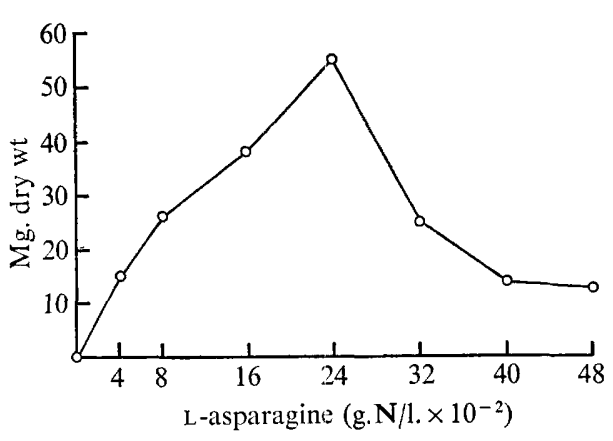

Fig. 9

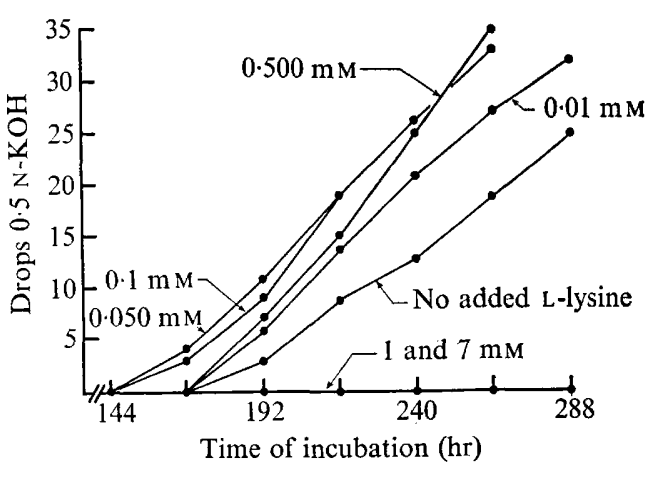

Fig. 10

Fig. 9. The relation between the growth of Catenaria anguillulae and the concentration of L-asparagine in Medium 5 at $\mathrm{pH} \mathrm{8.7.} \mathrm{Incubation} \mathrm{for} \mathrm{I} \mathrm{I} \mathrm{days.} \mathrm{Each} \mathrm{point} \mathrm{on} \mathrm{curve} \mathrm{average}$ of three replicates.

Fig. IO. The relation between the concentration of L-lysine added to Medium 5 containing $\mathrm{L}$-asparagine $(0 \cdot 24 \mathrm{~g} . \mathrm{N} / \mathrm{l}$.). as the $\mathrm{N}$ source and the production of titratable acid by Catenaria anguillulae. Initial $\mathrm{pH} 8 \cdot 7$.

single sources; of these, arginine was the one utilized from the mixture. One anomaly, namely lysine, stands out in the early uptake from the medium; this amino acid was not utilized in the earlier study dealing with single sources. Once the organism had passed through the lag phase into the more rapid period of growth, all of the amino acids in the mixture disappeared from the medium in significant amounts and were presumably utilized by the fungus.

Effects of the addition of L-lysine to a medium containing L-asparagine as the $N$ source. From the studies dealing with single $\mathrm{N}$ sources, L-asparagine emerged as the best source; this compound had the additional advantage that it was not utilized as a carbon source.

Because of the anomalous utilization of lysine from the Difco Casamino acids medium, the possibility that lysine might be a key to the problem of obtaining a shorter lag phase and a better yield was examined. Lysine might be a compound which was not utilized as a single source but which, when in a mixture with one or more other compounds which could be utilized as a $\mathrm{N}$ source, had a stimulatory effect. The medium used was Medium 5 adjusted to $\mathrm{pH} \mathrm{8.7.} \mathrm{L-asparagine} \mathrm{was} \mathrm{included} \mathrm{in} \mathrm{the}$ medium at the optimum concentration $(0 \cdot 24 \mathrm{~g}$. N/1.). L-lysine was added in concentrations varying from 0 (control) to $7 \mathrm{mM}$ (Table 8). The concentrations of $0 \cdot \mathrm{I}$ and $0.5 \mathrm{~mm}$ were more in accord with the concentrations utilized during the lag phase on the Difco Casamino acids medium $(0.244$ and $0.293 \mathrm{~mm}$ during the first 5-day and 6-day harvests, respectively). The growth of these cultures was followed on the basis of 
their production of titratable acid. The production of titratable acid was used to signify the end of the lag phase of growth, and hence the earlier production of such acid in the treatments to which 0.050 and $0.100 \mathrm{mM}$ of L-lysine had been added was taken as evidence of the shortening of the lag phase under these conditions (Fig. I0). This was in comparison to the additional $24 \mathrm{hr}$ required for the cultures in the control and other treatments (excluding the I and $7 \mathrm{~mm}$ treatments) to enter the phase of rapid growth. The rate of growth also appeared to be higher in all treatments with added lysine (except for the two highest concentrations) as compared to the control. Not only was the rate of growth higher, but the dry weights were considerably higher than those of the control (Table 8). From the dry weights at 240,263 and $283 \mathrm{hr}$, it can be seen that growth in the flasks containing the lower concentrations (0.010, 0.050 and $0.1 \mathrm{~mm})$ of added lysine had reached the peak of the growth curve after IO or I I days. At that time the control flasks were still growing rapidly and continued to do so through the I 2 th day of incubation when the experiment was terminated.

Table 8. The effects of added L-lysine on the growth of Catenaria anguillulae in Medium 5 with L-asparagine $(0.24 \mathrm{~g}$. $N / \mathrm{l}$.) as the nitrogen source

Dry weights are the averages of duplicate flasks. (pH 8.7)

\begin{tabular}{|c|c|c|c|}
\hline \multirow{2}{*}{$\begin{array}{c}\text { L-lysine } \\
\text { level } \\
\text { (mM) }\end{array}$} & \multicolumn{3}{|c|}{ Incubation period (hr) } \\
\hline & 240 & $\begin{array}{r}263 \\
y \text { we }\end{array}$ & 283 \\
\hline 0 & 19 & 47 & 79 \\
\hline $0.0 I$ & I I I & I IO & 116 \\
\hline 0.05 & 95 & II 8 & - \\
\hline 0.10 & 95 & I 22 & - \\
\hline 0.50 & 35 & 118 & 一 \\
\hline $\mathrm{I} \cdot \mathrm{OO}$ & - & - & I I \\
\hline $7 \cdot 00$ & - & - & 3 \\
\hline
\end{tabular}

The final medium evolved. Medium 7 (Table 2) was adopted as best satisfying the growth requirements of the isolate strain $58-\mathrm{I} 2$ of Catenaria anguillulae.

\section{DISCUSSION}

Couch (1945) observed the morphological similarities between the genera Catenaria and Blastocladiella; representatives of these two genera are unique within the Order Blastocladiales in their inability to utilize inorganic nitrogen. The high $\mathrm{pH}$ optimum of the isolate strain 58-I2 of Catenaria anguillulae used in the present work is unique among aquatic Phycomycetes; this is emphasized by its occurrence in regions of relatively alkaline $\mathrm{pH}$ value. For example, the fungus is found in the shallow margins of Lake George, Uganda, where the $\mathrm{pH}$ values often reach $\mathrm{pH}$ io (Dr L. G. Willoughby, personal communication to Dr R. Emerson; 29 November I966) and in some barnyards (personal communication from Dr F. K. Sparrow, Department of Botany, University of Michigan, Ann Arbor, 1967).

The early studies of Buckley \& Clapham (1929) and Butler \& Humphries (I932) on the growth and development of Catenaria were made by using one of its natural substrates, the eggs of the liver-fluke Fasciola hepatica L. Qualitative information is available on the amino acid composition of liver-fluke egg proteins (Krvavica, Maloseja, Wagner \& Martincic, I964). Of those amino acids utilized by Catenaria 
anguillulae in the present study, the eggs appear to contain proteins with high concentrations of arginine and lesser concentrations of glutamic acid and methionine; the eggs also contain stearic and oleic acids.

The author thanks Dr R. Emerson (Department of Botany) for his interest and encouragement throughout this work. The author also thanks Dr R. D. Cole (Department of Biochemistry) for the use of his amino acid analyser, and Dr L. Machlis (Department of Botany) for his advice.

\section{REFERENCES}

ARAI, T. \& KuWAHARA, S. (1961). Studies on the influence of minute amounts of fatty acids in bacteriological culture media on bacterial growth. I. Growth-accelerating action of trace amounts of fatty acids in vitamin-free casein hydrolysate on Streptococcus hemolyticus strain s-8. Japanese Journal of Microbiology 5, 327.

Brewer, J. H., Allgeier, F. L. \& McLaughlin, C. B. (1966). Improved anaerobic indicator. Applied Microbiology 14, I35.

Buckley, J. J. C. \& Clapham, P.(1929). The invasion of Helminth eggs by Chytridiacean fungi. Journal of Helminthology 7 , I.

BUtLeR, J. B. \& HUMPHRIES, A. (1932). On the cultivation in artificial media of Catenaria anguillulae, a chytridiacean parasite of the ova of the liver fluke, Fasciola hepatica. Scientific Proceedings of the Royal Dublin Society 20, 301.

Cantino, E. C. \& Turian, G. F. (1959). Physiology and development of lower fungi (Phycomycetes). Annual Review of Microbiology 13, 97.

Carlile, M. J. \& Machlis, L. (1965). The response of male gametes of Allomyces to the sexual hormone sirenin. American Journal of Botany 52, 478.

Couch, J. N. (1945). Observations on the genus Catenaria. Mycologia 37, I63.

Demain, A. L., Hendlin, D. \& NewkiRK, J. (1959). Role of fatty acids in the growth stimulation of Sarcina species by vitamin-free casein digests. Journal of Bacteriology 78, 839 .

Difco Manual. (I953). Ninth Edition. Detroit, Michigan: Difco Laboratories, Inc.

EMERSON, R.(194I). An experimental study of the life cycles and taxonomy of Allomyces. Lloydia 4, 77.

EMERSON, R. (1958). Mycological organization. Mycologia 50, 589.

GALE, E. F. (1945). The arginine, ornithine and carbon dioxide requirements of streptococci (Lancefield group D) and their relation to arginine dihydrolyase activity. British Journal of Experimental Pathology 26, 225.

Halvorson, H. C. \& Cowie, D. B. (1961). In Membrane Transport and Metabolism. Ed. by A. Kleinzeller \& A. Kotyk, p. 479. London: Academic Press.

Heller, C. L. (1954). A simple method for producing anaerobiosis. Journal of Applied Bacteriology I7, 202.

Kihara, H., Klatt, O. \& Snell, E. E. (1952). Peptides and bacterial growth. III. Utilization of tyrosine and tyrosine peptides by Streptococcus faecalis. Journal of Biological Chemistry 197, 801 .

Krvavica, S., Maloseja, Z., Wagner, H. \& Martincic, T. (1964). The amino acid composition of the proteins and the distribution of fatty acids in lipids of eggs of Fasciola hepatica and Ascaris suum. Veterinarski arhiv, Zagreb 34, 163.

MACHLIS, L. (1953). Growth and nutrition of water molds in the subgenus Euallomyces. II. Optimal composition of the minimal medium. American Journal of Botany 40, 450 .

MoORE, S. \& SteIN, W. H. (1963). Chromatographic determination of amino acids by the use of automatic recording equipment. Methods in Enzymology 6, 819.

Nolan, R. A. (1966). Nutritional studies with the aquatic Phycomycete Catenaria anguillulae. American Journal of Botany 53, 624.

Peters, V. J., Prescott, J. M. \& Snell, E. E. (1953). Peptides and bacterial growth. IV. Histidine peptides as growth factors for Lactobacillus delbrueckii 9649. Journal of Biological Chemistry 202, 521 .

Prescott, J. M., Peters, V. J. \& Snell, E. E. (1953). Peptides and bacterial growth. V. Serine peptides and growth of Lactobacillus delbrueckii 9649. Journal of Biological Chemistry 202, 533.

Steel, R. G. D. \& Torrie, J. H. (1960). Principles and Procedures of Statistics. New York: McGrawHill. 